\title{
First child protection guide launched
}

The first official guide to the dental team's role in child protection was recently launched by Health Minister Rosie Winterton, outlining the team's duties in the wake of the Victoria Climbié tragedy. Child protection and the dental team was commissioned and funded by the Department of Health, and follows work by paediatric dentists to explore how they should meet the challenges set by Lord Laming's inquiry into the death of eightyear-old Victoria Climbié, following a year of abuse. The inquiry criticised health professionals for missing numerous opportunities to protect her.

The new guide gives practical advice for the whole dental team on spotting the signs of abuse, ranging from physical injury to changes in behaviour and interaction with parents. It then gives guidance on what to do if you suspect a child is a victim of abuse. It also provides practical suggestions to help

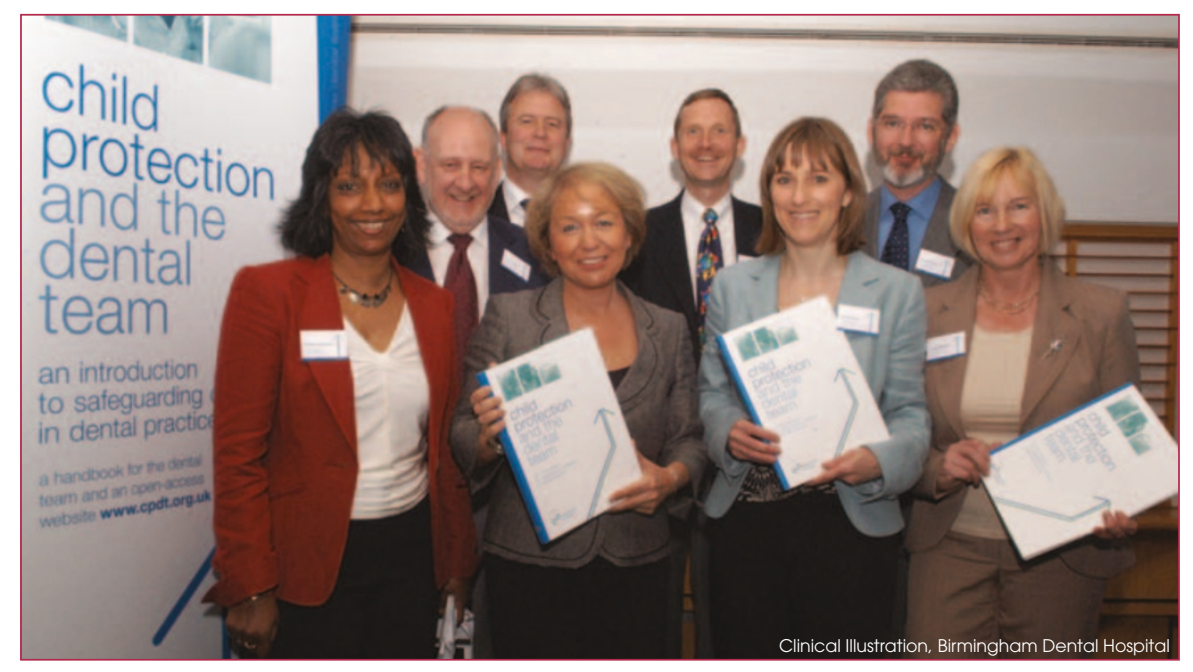

dental teams safeguard children, including advice on how to find out about local sources of help and further training.

The handbook is supported by an open- access website www.cpdt.org.uk. Pictured above, Health Minister Rosie Winterton with members of the expert group who developed the guide.

\section{Australia recognises UK dental nursing qualifications}

UK dental nursing qualifications will now be recognised in Australia, following negotiations between the British Association of Dental Nurses (BADN) and the Dental Assistants Education Council of Australia (DAECA).

Holders of the National Certificate or the S/NVQ 3 Oral Healthcare: Dental Nursing wishing to work in Australia will be able to apply for the DAECA certification and badge (cost approximately $£ 30$ ) by supplying DAECA with a copy of their qualification certificate and a letter confirming their BADN membership.

The Federal and State Branches of the Australian Dental Association and the Office of Overseas Skills Recognition have been informed that both the National Certificate and the S/NVQ 3 are now recognised by the DAECA.

BADN President Michelle Brindley said: 'Many young dental nurses decide to broaden their horizons by travelling and working abroad, and Australia - with its scheme for the under 30 s - is a popular destination. BADN are now hoping to reach similar agreements with other countries.'

Dental nurses planning to work in Australia and wishing to obtain DAECA recognition of their UK qualification should contact BADN on 01253338360 , admin@badn.org.uk or visit the BADN website www.badn.org.uk for more details.

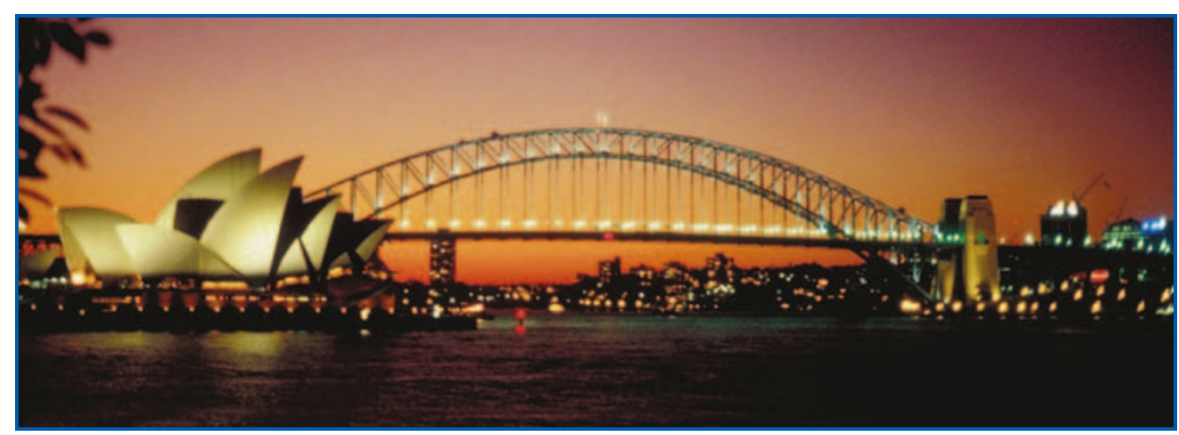

\section{Home oral hygiene works}

According to a study in the Journal of Periodontology, brushing and flossing teeth are essential to the daily hygiene routine.

In the study, 51 sets of twins aged 12-21 were examined for gingival bleeding and halitosis. Each set was then divided into two groups. One group manually brushed their teeth and tongue twice a day for two weeks. The second group did the same but also used dental floss twice a day. After two weeks, they were examined again.

Twins were examined in this study because each set shares the same dietary habits, health and life practices.

Researchers found that tongue and tooth brushing in combination with flossing significantly decreased gingival bleeding by $38 \%$ after two weeks and reduced halitosis. In the group that did not floss, gingival bleeding sites increased by almost $4 \%$.

'A good way to prevent periodontal disease and tooth decay is through at-home oral hygiene and routine dental visits,' said Walter A. Bretz at the New York University College of Dentistry. 